\title{
Nutritional status and hygiene practices of primary school children
}

\begin{abstract}
Background: Despite the economic growth observed in developing countries, malnutrition is still highly prevalent. The school age is a dynamic period of growth and development. Poor health and malnutrition may impair both the growth and cognitive development of primary school children. The aim of this study carried out the nutritional status and basic hygiene practice among the primary school children in Dhaka city, Bangladesh.
\end{abstract}

Methods: This was a cross-sectional study conducted among 110 primary school children aged between 6 to 12 years at Nilkhet High School in Dhaka city, Bangladesh. The samples were selected by using simple random method and face to face interview adopted through semi structured questionnaire. Nutritional status was determined by according to WHO classification. Collected data were analyzed by using SPSS version of computer technology.

Result: Among respondents $66.40 \%(73)$ were boys and $33.60 \%(37)$ were girls. In case of WAZ, $19.10 \%$ were below normal, $79.10 \%$ were normal and $1.80 \%$ was above normal. In case of HAZ, $11.80 \%$ were below normal, $80 \%$ were normal and $2.70 \%$ were above normal. And in case of WHZ $18.20 \%$ were below normal, $55.50 \%$ were normal and $1.80 \%$ were above normal. Regarding hygiene practice, $100 \%$ respondents washed hand before and after meal, as well as $99.10 \%$ washed hand after coming home from outside area. For brushing teeth, 34.2\%(25), 57.5\%(42) and 8.2\%(6) boys brushed teeth one, two and three times everyday respectively, where $21.6 \%(8), 56.8 \%(21)$ and $21.6 \%(8)$ girls brushed teeth one, two and three times everyday respectively.

Conclusion: This study showed that malnutrition is widely prevalent among primary school children. Appropriate screening in school health program and proper nutrition education program may be recommended as early as possible.

Keywords: nutritional status, hygiene practice, school children
Volume I Issue I - 2014

\author{
Monoarul Haque, ' Yasin Arafat, ${ }^{2}$ Suman \\ Kumar Roy, ${ }^{2}$ Md Zahid Hasan Khan, ${ }^{3}$ AKM \\ Majbah Uddin, ${ }^{4}$ Shafiullah Pradhania ${ }^{5}$ \\ 'Department of Community Nutrition, Bangladesh University of \\ Health Sciences (BUHS), Bangladesh \\ 2Bangladesh University of Health Sciences (BUHS), Bangladesh \\ ${ }^{3}$ Community Medical Institute, Bangladesh \\ ${ }^{4}$ Department of Public Health and Life Sciences, University of \\ South Asia, Bangladesh \\ ${ }^{5}$ Bangladesh Medical College, Bangladesh
}

\begin{abstract}
Correspondence: Monoarul Haque, Department of Community Nutrition, Faculty of Public Health, Bangladesh University of Health Sciences(BUHS), I25/I, Darus Salam, Mirpur, Dhaka 1216, Bangladesh, Tel 008801915839550, Email monoarmunna@yahoo.com
\end{abstract}

Received: April 28, 2014 | Published: May 12, 2014
Abbreviations: WAZ, weight-for-age z-scores; HAZ, heightfor-age z-scores; WHZ, weight-for-height z-scores; BMI, body mass index

\section{Introduction}

In modern age malnutrition continues to be a serious public health problem. ${ }^{1}$ Despite the economic growth observed in developing countries, malnutrition and particularly under-nutrition is still highly prevalent. $^{2}$ Malnutrition is usually the result of a combination of inadequate dietary intake and infection. In children, malnutrition is synonymous with growth failure. Malnourished children are shorter and lighter in weight than they should be for their age. ${ }^{3}$ With the high incidence of poverty and HIV/AIDS, prevalence of malnutrition is also high. ${ }^{4}$ Malnutrition needs to be viewed as an indication of inadequate provision of some of the most basic of all human rights. It is also a reflection of inadequate investment and progress in a range of issues related to human capital development and has a significant influence on the future economic development of a country. ${ }^{5}$ Some studies are now highlighting the problem of micronutrient deficiencies among schoolchildren in particular. ${ }^{6,7}$ The school age is a dynamic period of growth and development. During this period physical, mental, social development of child takes place. ${ }^{8}$ Poor health and malnutrition may impair both the growth and cognitive development of primary school children. School children are dramatically affected by anemia, vitamin A deficiency ${ }^{9}$ and parasitic infections ${ }^{10}$ with adverse impact on their nutritional status ${ }^{10,11}$ as well as on their cognitive development and school performance also. ${ }^{12-15}$ There is growing evidence of considerable burden of morbidity and mortality due to infectious diseases and malnutrition in school children in developing countries. Studies in different countries identified the following in primary school children: respiratory problems, diarrheal disease, nutritional disorders, anemia, parasitic infestations, pediculosis, caries teeth, refractive errors, skin diseases, ear and throat problems, tic disorders, sleeping disorders etc. ${ }^{15-27}$ Stunting and wasting are wide spread among school age children in developing countries. ${ }^{28-32}$ High levels of stunting among children suggest that there will also be a long term deficit in mental and physical development that leaves children unable to take maximum advantage of learning opportunities in schools. Epidemiological evidences suggest a strong link between maternal and early childhood under nutrition and increased adult risk of various chronic diseases. ${ }^{33}$ According to WHO criteria, $52 \%$ of school going children in under developed countries are considered normal, where $48 \%$ of them are malnourished and $10 \%$ of them are severely malnourished. ${ }^{34}$ More than 200million school children are stunted and if no action is taken and at this rate, about 1 billion stunted school age children will be growing up by 2020 with impaired physical and mental development. ${ }^{35}$ Bangladesh is also facing high poverty and child under-nutrition rates. ${ }^{36}$ More than $54 \%$ of preschool-age children, equivalent to more than 9.5 million children, are stunted, $56 \%$ are underweight and more than $17 \%$ are wasted. ${ }^{37}$ Almost same condition will found when this children starts to go school. 
In the developing countries like Bangladesh, due to poor hygiene practices the school-age children often experience increased burden of communicable diseases that decreases their ability to attend school regularly and to learn their full potential also. ${ }^{38} \mathrm{~A}$ large fraction of the world's illness and death is attributable to communicable diseases. ${ }^{39}$ Sixty-two percent and $31 \%$ of all deaths in Africa and Southeast Asia, respectively, are caused by infectious disease. ${ }^{40}$

The aim of this study was to assess the nutritional status and their hygiene practice among the primary school children in urban area of Dhaka city in Bangladesh.

\section{Methodology}

\section{Study design}

This was a cross-sectional study conducted in 2012.

\section{Study area and population}

From January 2012 to June 2012, we conducted this study in the Nilkhet High School, situated in Nilkhet area of Dhaka metropolitan city of Bangladesh. Although Nilkhet is in urban area but this place is highly dense with low and middle income people. Students in primary level age between 6 to 12years in Nilkhet high school were the population of this study.

\section{Study sample and sampling method}

We adopted random sampling method to conduct this study. About 110 children were assigned randomly to collect data.

\section{Data collection tools and techniques}

A questionnaire was developed containing both closed and open ended questions to obtain relevant information on socioeconomic, anthropometric, and hygiene practice. All questions were designed, pre-tested, modified and resettled to obtain as well as record information easily. The purpose of the pre-test was to test the content, working expression, the topical sequence of questions, duration of the interview and the reliability of some items. After pre-test the individual questionnaire which was related for quantitative data, improved and reformed to ensure content coverage, the reliability and validity of the study.

\section{Age detection}

Age of the subjects under study was determined by interrogation and confirmed through probing. The age of the children was collected from the school record as well as respondents itself. If it was not possible to ensure approximate age by asking some local and national incidence occurred at that period.

The anthropometrical data (weight and height) were taken individually by the following standard Procedure:

\section{Measuring body weight}

Weight was recorded in kilograms by using standard weighting machine. During measuring weight, each subject was asked to bare footed and to remove heavy cloth.

\section{Measuring height}

For measurement of height, subjects were positioned to stand on the platform, bare footed with their head upright, looking straight forward by using standard height measurement scale. Height was measured to the nearest $0.1 \mathrm{~cm}$.

\section{Data verification}

Questionnaires were checked each day after interviewing and again these were carefully checked after completion of all data collection and coded before entering into the computer. To minimize the errors, after entering the data set into the computer, these are checked and resolved by correction.

\section{Assessment of nutritional status}

The nutritional status of school children was assessed by anthropometric measurements viz., height in centimetre $(\mathrm{cm})$ and weight in kilograms $(\mathrm{kg})$. It was determined by Z-score value according to WHO classification.

\section{Assessment of hygiene practice}

Some basic hygiene practice related questions were asked like hand washing practice, brushing practice, using sandal all day.

\section{Data analysis}

Data were processed and analyzed statistically by using SPSS 15 software. To ensure data quality, data of $30 \%$ of the records were entered twice.

\section{Ethical issues}

Initially explained the purpose and objective of the study to the Headmistress and permission was taken to conduct this study. Verbal consent was taken from mothers and as well as from children who were able to understand. This was a self funding study and no external fund was provided to carry out this study.

\section{Results}

Table 1 shows that among 110 school children $66.40 \%(73)$ were boys and $33.60 \%(37)$ were girls. In the age distribution, $1.80 \%(2)$ children were boys and $2.72 \%(3)$ were girls whose age was 7 years . About 20\%(22) were boys and $9.09 \%(10)$ were girls whose age was 8years . Similarly, $13.63 \%(15)$ and $10.90 \%(12)$ were boys and girls in the age of 9years . $18.18 \%(20)$ and $7.27 \%(8)$ were boys and girls in the age of 10years . About $8.18 \%(9)$ and $2.72 \%(3)$ were boys and girls in the age of 11years and 4.54\%(5) and $0.90 \%(1)$ were boys and girls in the age of 12 years. In case of father's occupation of school children, $55.50 \%(61)$ were Government service holder, $27.30 \%(30)$ were in private job and $17.30 \%(19)$ were business man. In case of mother's occupation, $9.10 \%(10)$ mothers engaged job and $90.90 \%(100)$ mothers was housewife. About 50\%(55), 46.4\%(51) and $3.6 \%$ (4) school children had sibling one to two, three to four and more than four respectively.

Table 2 showed that among 110 school children, about $93.6 \%(103)$ respondents were underweight, $6.4 \%(7)$ were normal and no overweight had found.

Table 3 showed $19.1 \%, 11.8 \%$ and $18.2 \%$ of children suffered moderate underweight, stunting and wasted respectively.

Table 4 showed that $93.60 \%$ children had BMI below normal and $6.40 \%$ children had normal BMI and no overweight has found. In case of WAZ, $19.10 \%$ were below normal, $79.10 \%$ were normal and $1.80 \%$ was above normal. In case of HAZ, $11.80 \%$ were below normal, $80 \%$ 
were normal and $2.70 \%$ were above normal. And in case of WHZ $18.20 \%$ were below normal, $55.50 \%$ were normal and $1.80 \%$ were above normal

In case of basic hygiene practice, $100 \%$ respondents washed hand before and after meal, $99.10 \%$ washed hand after coming home from outside area. For brushing teeth, 34.2\%(25), 57.5\%(42) and 8.2\%(6) boys brushed teeth one, two and three times everyday respectively, where $21.6 \%(8), 56.8 \%(21)$ and $21.6 \%(8)$ girls brushed teeth one, two and three times everyday respectively. In case of using sandal all the day $97.3 \%(71)$ boys used sandal where $2.7 \%$ (2) boys didn't use sandal all the day and $81.1 \%(30)$ girl used sandal where $8.2 \%(9)$ girls didn't use sandal all the day (Table 5).

Table I Socio-demographic characteristics of the school children $(n=1 \mid 0)$

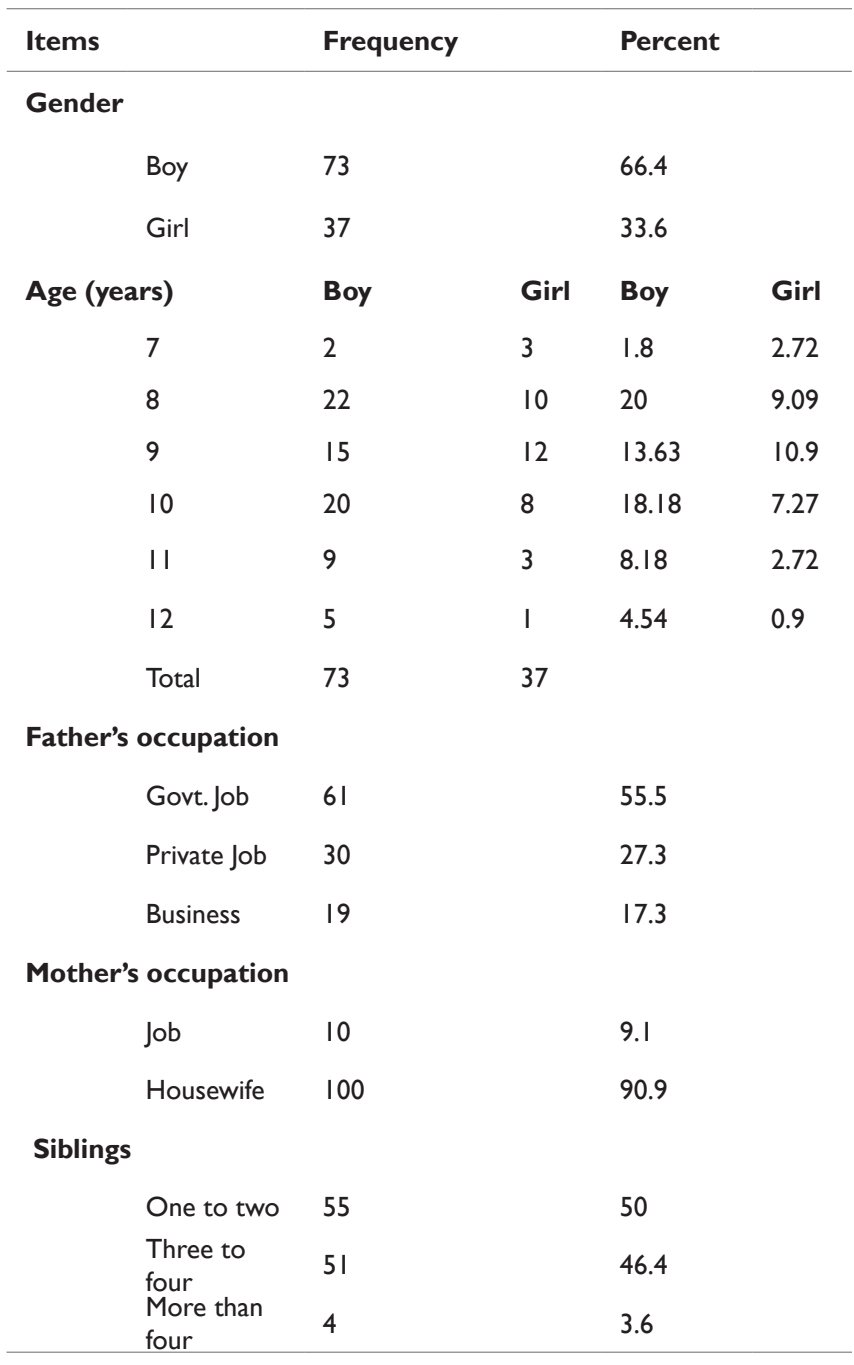

Table 5 Distribution of Hygiene practice of school children $(n=\mid 10)$
Table 2 Nutrition status of children $(n=|| 0)$

\begin{tabular}{lll}
\hline Status & Frequency & Percent \\
\hline Underweight & 103 & 93.6 \\
Normal & 7 & 6.4 \\
Total & 110 & 100.0
\end{tabular}

Table 3 Distribution of weight for age, height for age and weight for height Z-score $(n=110)$

\begin{tabular}{lll}
\hline Range & Frequency & Percent \\
\hline$<-2.00$ SD & WAZ & \\
-2.00 to +1.99 SD & 87 & 19.1 \\
2.00 to 2.99 SD & 2 & 79.1 \\
Total & 110 & 1.8 \\
& HAZ & 100.0 \\
$<-2.00$ SD & 13 & 11.8 \\
-2.00 to $+1.99 S D$ & 88 & 80.0 \\
2.00 to $2.99 S D$ & 3 & 2.7 \\
$>=3.00 S D$ & 6 & 5.5 \\
Total & 110 & 100.0 \\
& WHZ & \\
Valid <-2.00SD & 20 & 18.2 \\
-2.00 to $+1.99 S D$ & 61 & 55.5 \\
2.00 to $2.99 S D$ & 2 & 1.8 \\
Total & 83 & 75.5 \\
Missing system & 27 & 24.5 \\
Total & 110 & 100.0 \\
\hline
\end{tabular}

WAZ, weight for age; HAZ, height for age;WHZ, weight for height

Table 4 Summary of nutritional status $(n=110)$

\begin{tabular}{lllll}
\hline \multirow{2}{*}{$\begin{array}{l}\text { Nutritional } \\
\text { status }\end{array}$} & \multicolumn{4}{l}{ Students (\%) } \\
\cline { 2 - 4 } & BMI & WAZ & HAZ & WHZ \\
\hline Under the Normal & 93.60 & 19.10 & 11.80 & 18.20 \\
Normal & 06.40 & 79.10 & 80.00 & 55.50 \\
Over the Normal & 00.00 & 01.80 & 02.70 & 01.80 \\
Obese & 00.00 & 00.00 & 05.50 & 00.00 \\
\hline
\end{tabular}

$B M I$, body mass index;WAZ, weight for age; $\mathrm{HAZ}$, height for age; WHZ, weight for height

\begin{tabular}{llll}
\hline Hand washing practice & & & \\
\hline Category & Wash hand (\%) & Do not wash hand (\%) & Irregularly wash hand (\%) \\
\hline Before meal & $100(110)$ & $0.00(0)$ & $0.00(0)$ \\
After toilet with soap & $100(110)$ & $0.00(0)$ & $0.00(0)$ \\
After coming home from outside & $99.10(109)$ & $0.90(01)$ & $0.00(0)$ \\
area & & & \\
\hline
\end{tabular}


Table continued..

\section{Hand washing practice \\ Brushing teeth practice}

Sex

$\begin{array}{ll} & \text { Count } \\ \text { Boy } & \text { \% within Sex } \\ \text { Girl } & \text { Count } \\ \text { Total } & \text { \% within Sex } \\ & \text { Count } \\ & \% \text { within Sex }\end{array}$

Using sandal all the day

$\begin{array}{ll} & \\ \text { Boy } & \text { Count } \\ & \% \text { within Sex } \\ \text { Girl } & \text { Count } \\ & \% \text { within Sex } \\ \text { Total } & \text { Count } \\ & \% \text { within Sex }\end{array}$

\section{Discussion}

Study showed that majority $(93.6 \%)$ of the school children were suffering from under weight(BMI) and very few $(6.4 \%)$ of them had normal BMI. Similar findings had found in the study done by Adhikary $\mathrm{M}$ et al., ${ }^{40}$ among primary school children in one Upazila(sub district) where it was found that more than two third children were underweight. ${ }^{41}$ According to WHO $48 \%$ of children were malnourished and $10 \%$ of them were severely malnourished. ${ }^{34}$ In case of WAZ, more than two thirds(79.10\%) were normal. In case of HAZ, almost majority $(80 \%)$ were normal and in case of WHZ, more than half( $55.50 \%)$ were normal range. Previous study found that more than $54 \%$ of preschool-age children, equivalent to more than 9.5 million children, were stunted, $56 \%$ were underweight and more than $17 \%$ were wasted. ${ }^{37,42,43}$

Study found that almost all(99.10\%) children washed hand before taking meal. More than half of boys $(57.5 \%)$ and girls $(56.8 \%)$ brushed teeth two times every day and majority $(91.81 \%)$ of the children used sandal all the day. This finding showed the improvement of hygiene practice among the school children in Bangladesh. ${ }^{32-34}$

\section{Conclusion}

This study provides that malnutrition among the primary school children is still high. Hence, screening for common health problems with assessment of nutritional status is essential for school health program. Although the findings of this study can't be generalize but still it represents the similar findings of other studies. However, early detection and appropriate treatment for malnourished children must be done prior to school entry, otherwise this will create huge burden for the nation.

\section{Acknowledgments}

None.

\section{Conflict of interest}

Author declares that there is no conflict of interest.

\begin{tabular}{llll}
\multicolumn{4}{l}{ Frequency of brushing teeth } \\
One & Two & Three & Total \\
25 & 42 & 6 & 73 \\
$34.2 \%$ & $57.5 \%$ & $8.2 \%$ & $100.0 \%$ \\
8 & 21 & 8 & 37 \\
$21.6 \%$ & $56.8 \%$ & $21.6 \%$ & $100.0 \%$ \\
33 & 63 & 14 & 110 \\
$30.0 \%$ & $57.3 \%$ & $12.7 \%$ & $100.0 \%$
\end{tabular}

$\begin{array}{lll}\begin{array}{lll}\text { Sandal using } \\ \text { Use sandal }\end{array} & \begin{array}{l}\text { Do not use } \\ \text { sandal }\end{array} & \text { Total } \\ 71 & 2 & 73 \\ 97.3 \% & 2.7 \% & 100.0 \% \\ 30 & 7 & 37 \\ 81.1 \% & 18.9 \% & 100.0 \% \\ 101 & 9 & 110 \\ 91.8 \% & 8.2 \% & 100.0 \%\end{array}$

\section{References}

1. UNICEF. Malnutrition: causes, consequences and solution. The state of the world's children. 1998

2. Muller O, Krawinkel M. Malnutrition and health in developing countries. CMAJ. 2005;173(3):279-286.

3. United Nations International Children's Education Fund (UNICEF). Water, Sanitation, and Hygiene Annual Report. 2009:5-19

4. World Health Organization (WHO). Towards the realization of free basic sanitation: Evaluation, Review and Recommendations. WRC Project. WHO. 2010.

5. Health, Nutrition \& population Sector. Government of People's Republic of Bangladesh, Ministry of Health \& Family welfare, Human resource management, Planning and development Unit. 2010.

6. Hall A, Bobrow E, Brooker S, et al. Anaemia in schoolchildren in eight countries in Africa and Asia. Public Health Nutr. 2001;4(3):749-756.

7. Hasan MM, Hoque MA, Hossain MA, et al. Nutritional status among primary school children of Mymensingh. Mymensingh Med J. 2013;22(2):267-274

8. Singh V, West KP. Vitamin A deficiency and xerophthalmia among schoolaged children in Southeastern Asia. Eur JClin Nutr. 2004;58(10):1342-1349.

9. Brooker S, Clements ACA, Hotez PJ, et al. The co-distribution of Plasmodium falciparum and hookworm among African schoolchildren. Malar J. 2006;5:99.

10. Awasthi S, Bundy D. Intestinal nematode infection and anaemia in developing countries. BMJ. 2007;334(7603):1065-1066.

11. Casapia M, Joseph SA, Nunez C, et al. Parasite risk factors for stunting in grade 5 students in a community of extreme poverty in Peru. Int $J$ Parasitol. 2006;36(7):741-747.

12. Pollitt E. Early iron deficiency anemia and later mental retardation. Am J Clin Nutr. 1999;69(1):4-5.

13. Singh M. Role of micronutrients for physical growth and mental development. Indian J Pediatr. 2004;71(1):59-62.

14. Florence MD, Asbridge M, Veugelers PJ. Diet quality and academic performance. J Sch Health. 2008;78(4):209-215. 
15. Ong SG, Liu J, Wong CM, et al. Studies on the respiratory health of primary school children in urban communities of Hong Kong. Sci Total Environ. 1991;106(1-2):121-135.

16. Berger IB, Salehe O. Health status of primary school children in central Tanzania. J Trop Pediatr. 1986;32(1):26-29.

17. Shakya SR, Bhandary S, Pokharel PK. Nutritional status and morbidity pattern among governmental primary school children in the Eastern Nepal. Kathmandu Univ Med J. 2004;2(4):307-314.

18. Chopdar A, Mishra PK. Health status of rural school children in Western Orissa. Indian J Pediatr. 1980;47(386):203-206.

19. Gupta BS, Jain TP. A comparative study of the health status of rural and urban primary school children. Indian J Pediatr. 1973;40(303):135-141.

20. Gupta RK, Bhat A, Khajuria RK, et al. Health status of primary school children in Jammu. Indian Journal of Preventive \& Social Medicine. 1997;28(3\&4):90-94.

21. Wandera M, Twa-Twa J. Baseline survey of oral health of primary and secondary school pupils in Uganda. Afr Health Sci. 2003;3(1):19-22.

22. Ng'ang'a PM, Valderhaug J. Oral hygiene practices and periodontal health in primary school children in Nairobi, Kenya. Acta Odontol Scand. 1991;49(5):303-309.

23. Al-Haddad AM, Hassan HS, Al-Dujaily AA. Distribution of dental caries among primary school children in Al-Mukalla area - Yemen. Journal of Dent. 2006;3:195-198.

24. Mohammad K, Mohammadreza G, Mohammdi Z. Prevalence of Refractive Errors in Primary School Children [7-15Years] of Qazvin City. European Journal of Science and Research. 2009;28:174-185.

25. Lanzi G, Zambrino CA, Termine C, et al. Prevalence of tic disorders among primary school students in the city of Pavia, Italy. Arch Dis child. 2004;89(1):45-47.

26. Uncu Y, Irgil E, Karadag M. Smoking patterns among primary school students in Turkey. Scientific World J. 2006;6:1667-1673.

27. Al Bashtawy M, Hasna F. Pediculosis capitis among primary-school children in Mafraq Governorate, Jordan. East Mediterr Health J. 2012;18(1):43-48.

28. Druck B. The dance of climate change and hidden hunger. The Sight and Life Magazine. 2010;3:40-59.

29. Kadiyata S, Gillespie S. Rethinking food aid to fight AIDS. International nutrition foundation for United Nations University. Food \& Nutrition Bulletin. 2004;25(3):33-41.
30. World Health Organization. Children schools and health; their nutrition and health in Kenya. WHO Global database on child growth and malnutrition. 2012:17-20.

31. Burbano C, Bundy D, Grosh M, et al. Rethinking School Feeding: Social Safety Nets, Child Development and the Education Sector. The International Bank for Reconstruction and Development/the World Bank. Washington DC; 2009:33-36.

32. Allen LH, Gillespie SR. What Works? A Review of the Efficacy and effectiveness of Nutrition Interventions. United Nations Administrative Committee on coordination Sub-Committee on Nutrition. Asian Development Bank. 2001:8-16.

33. United Nations International Children's Education Fund (UNICEF). Nutritional assessment in Kenya, Nairobi, Kenya. 2000:1-12.

34. UNICEF. Food \& Nutrition Bulletin (supplement). 2006;21(3):6-17.

35. World Food Programme. Overview of Bangladesh. 2013.

36. Nutrition and consumer protection: Bangladesh summary. FAO. 2010.

37. Hussain MA. A study on knowledge and practice of personal hygiene among school children in rural areas of Bangladesh. American Public Health Association. 2012.

38. Better Health for Poor Children. World Health Organization. 2002.

39. Curtis VA, Danquah LO, Aunger RV. Planned, motivated and habitual hygiene behaviour: an eleven country review. Health Educ Res. 2009;24(4):655-673

40. Adhikary M. Nutritional status among primary school children in a Upozila of Bangladesh. Northern International Medical College Journal. 2013;4(2):265-268.

41. Ara R, Hoque SR, Adhikari M, et al. Nutritional status among the primary school children in a selected rural community. J Dhaka Med Coll. 2011;20(2):97-101.

42. Shariff ZM, Bond J, Johson N. Nutritional status of primary school children from low income households in kuala lumpur. Malays $J$ Nutr. 2000;6(1):17-32.

43. Sharmin AS. Hygiene promoters teach safe sanitation practices in Bangladesh. 2008. 